\title{
The incidence of cough induced by remifentanil during anesthetic induction was decreased by graded escalation of the remifentanil concentration
}

\author{
Ji Hun Lim, Sie Jeong Ryu, and Young Soo Lim \\ Department of Anesthesiology and Pain Medicine, Kosin University College of Medicine, Busan, Korea
}

Background: It is well known that opioids induce coughing. Many drugs such as lidocaine and ketamine are used to effectively prevent the coughing induced by opioids and this has been revealed to be effective. In this study, we evaluated the preventive effect of a graded escalation of the remifentanil concentration using a target controlled infusion pump and we compared this with the effect of lidocaine.

Methods: One hundred fifty ASA I and II patients who were scheduled for elective surgery were randomly divided into 3 groups. The patients were pretreated with $2 \%$ lidocaine $1 \mathrm{mg} / \mathrm{kg}$ (Group L) or saline (Group S) and remifentanil infusion (an effect site concentration of $4.0 \mathrm{ng} / \mathrm{ml}$ ) was followed 1 minute later by using a target controlled infusion pump. Group R was pretreated with saline and this was followed by remifentanil infusion (effect site concentration of $2.0 \mathrm{ng} / \mathrm{ml}$ at first and then it was reset to $4.0 \mathrm{ng} / \mathrm{ml}$ ). We evaluated the incidence, severity and onset time of cough after remifentanil infusion.

Results: The incidence of coughing was significantly decreased in Group R (6 cases, 12\%) and Group L ( 7 cases, $14 \%)$, as compared to that of Group S (17 cases, 34\%) $(\mathrm{P}<0.05)$, but there was no significant difference between Group R and Group L. The groups showed no significant difference in the severity and the onset time of coughing.

Conclusions: This study demonstrated that administering graded escalation of the remifentanil concentration suppresses remifentanil-induced coughing as effectively as lidocaine $1 \mathrm{mg} / \mathrm{kg}$ pretreatment. (Korean J Anesthesiol 2010; 58: 117-121)

Key Words: Cough, Graded escalation, Lidocaine, Remifentanil.

Received: December 10, 2009. Revised: December 25, 2009. Accepted: December 31, 2009.

Corresponding author: Sie Jeong Ryu, M.D., Department of Anesthesiology and Pain Medicine, Kosin University College of Medicine, 34, Amnam-dong, Seo-gu, Busan 602-030, Korea. Tel: 82-51-990-6265, Fax: 82-51-254-2504, E-mail: siejeong@ns.kosinmed.or.kr (c)This is an open-access article distributed under the terms of the Creative Commons Attribution Non-Commercial License (http:// creativecommons.org/licenses/by-nc/3.0/), which permits unrestricted non-commercial use, distribution, and reproduction in any medium, provided the original work is properly cited. 


\section{Introduction}

Remifentanil has a rapid onset time and a short contextsensitive half time, so it is useful as an adjuvant for inhalational anesthesia and total intravenous anesthesia. It is effective in reducing the perioperative hemodynamic, the autonomic responses and the somatic responses [1]. Although it was known that opioid suppresses the cough reflex during tracheal intubation, administrating a small amount of remifentanil was reported to cause coughing just like administering fentanyl [2]. The incident rate of remifentanil-induced coughing is about $27-28 \%[2,3]$. Coughing during anesthetic induction can increase the intracranial pressure, the intraocular pressure and the intraperitoneal pressure. Continuous coughing may sometimes require sedatives or muscle relaxants [4]. Many methods are used during anesthetic induction to reduce the occurrence of fentanyl-induced and remifentanil-induced coughing. The intravenous administration of selective beta- 2 agonists (terbutaline and salbutamol), lidocaine and ketamine are known to reduce fentanyl-induced and remifentanilinduced coughing [2,3,5-8]. Lin et al. [9] reported that the prolonged injection time and the slow administration of fentanyl decreased the incidence of fentanyl-induced coughing. However, there have been no research studies published on the effects of a prolonged injection time and the graded escalation of remifentanil to reduce remifentanil-induced coughing.

The objective of the study was to determine if the graded escalation of the remifentanil concentration using a targetcontrolled infusion pump is effective for reducing remifentanilinduced coughing. The effect of a graded escalation of the remifentanil concentration was also compared with the effect of lidocaine pretreatment.

\section{Materials and Methods}

The subjects were 150 men and women patients between the ages of 20 and 60, ASA I and II, and they were undergoing an elective operation under general anesthesia. With the permission of the local institutional review board, we explained to the patients during the preanesthetic visit about the research study and we obtained their permission to include them into the study. We excluded those patients with bronchial asthma, chronic obstructive pulmonary disease, respiratory tract infection, hypertension and allergy to local anesthetics, and the smokers from the study group.

We did not perform anesthetic premedication. Before arriving in the operating room, vascular access was secured with an $18 \mathrm{G}$ needle in the patient's forearm, and we started fluid administration using lactate Ringer's solution. When the patient arrived in the operating room, an electrocardiograph, a noninvasive blood pressure manometer and a pulse oximeter were placed for monitoring. The patients were randomly divided into 3 groups with 50 patients in each group. Group L was intravenously injected with $2 \%$ lidocaine $1 \mathrm{mg} / \mathrm{kg}$. After 1 minute, the remifentanil's effect site concentration was set at $4.0 \mathrm{ng} / \mathrm{ml}$ using a target controlled infusion pump (TCI, [Orchestra ${ }^{\circledR}$ Fresenius Vial, Brezims, France]). In Group S, we administered normal saline of the same amount as the $2 \%$ lidocaine ( $1 \mathrm{mg} / \mathrm{kg})$. After 1 minute, remifentanil's effect site concentration was set at $4.0 \mathrm{ng} / \mathrm{ml}$ with the TCI pump. Group R was administered normal saline of the same amount as the $2 \%$ lidocaine $(1 \mathrm{mg} / \mathrm{kg})$. One minute after this, remifentanil's effect site concentration was set at $2.0 \mathrm{ng} / \mathrm{ml}$. When the effect site concentration reached $2.0 \mathrm{ng} / \mathrm{ml}$, it was reset at $4.0 \mathrm{ng} / \mathrm{ml}$ and administered by graded escalation. When the remifentanil's effect site concentration reached $4.0 \mathrm{ng} / \mathrm{ml}$, the propofol's effect site concentration was set at $4.0 \mathrm{ug} / \mathrm{ml}$ followed by continuous infusion. Loss of consciousness was observed. After administering remifentanil, an observer who was not informed about the administered drugs recorded the onset time of coughing (from the beginning of TCI to the beginning of coughing) and the cough severity over the period of 1 minute. The cough severity was evaluated by the number of coughs (light: $1-2$, moderate: $3-4$, severe: $5+$ ). During the patient observation, $100 \%$ oxygen was administered immediately by mask when the oxygen saturation fell below $95 \%$. We evaluated for any apnea and/or muscle rigidity. Apnea was defined as when breathing stopped for more than 15 seconds. Muscle rigidity was defined as increased tone of the trunk muscles, where ventilation with the face mask was difficult or not possible. After remifentanil administration, we administered propofol and recorded the incidence of pain. The severity of pain was recorded on a scale of $0-3$ (pain score 0 : negative response to question, 1 : pain in response to questioning only without any behavioral signs, 2: pain in response to questioning and accompanied by behavioral signs or pain reported spontaneously without questioning, 3: strong vocal response or response accompanied by facial grimacing, arm withdrawal or tears).

SPSS 13.0 was used for the statistical analysis. The statistical measurement was shown as the number of patients or mean \pm standard deviation. The gender ratio and physical status were compared by chi-square tests, and other factors of the patients characteristics were compared using one-way ANOVA test. For analysis of the results, comparing the incidence of coughing and the severity of pain after propofol administration was done using the chi-square test. Comparing the time of onset of cough was done with the one-way ANOVA test. $\mathrm{P}<0.05$ was defined as statistically significant. 


\section{Results}

There were no differences of the characteristics amongst the 3 groups (Table 1). None of the patients experienced hypoxia, apnea, muscle rigidity of the trunk or other side-effects after remifentanil administration.

The incidence of coughing was significantly lower in Group $\mathrm{R}$, which received graded escalation of remifentanil (6 patients, $12 \%)$, and Group L, which received lidocaine administration (7 patients, 14\%), than that in Group S, which received normal saline administration (17 patients, 34\%) (Fig. 1, P < 0.05). However, there was no significant difference between Group

Table 1. The Patients' Characteristics and the Remfentanil Dose

\begin{tabular}{lccc}
\hline & $\begin{array}{c}\text { Group S } \\
(\mathrm{n}=50)\end{array}$ & $\begin{array}{c}\text { Group R } \\
(\mathrm{n}=50)\end{array}$ & $\begin{array}{c}\text { Group L } \\
(\mathrm{n}=50)\end{array}$ \\
\hline Sex $(\mathrm{M} / \mathrm{F})$ & $16 / 34$ & $19 / 31$ & $14 / 36$ \\
ASA physical status (I/II) & $35 / 15$ & $39 / 11$ & $39 / 11$ \\
Age (yr) & $43.4 \pm 10.3$ & $43.1 \pm 10.9$ & $44.0 \pm 9.0$ \\
Height $(\mathrm{cm})$ & $164.0 \pm 8.6$ & $164.5 \pm 8.9$ & $162.4 \pm 6.8$ \\
Weight $(\mathrm{kg})$ & $63.0 \pm 10.9$ & $63.7 \pm 11.3$ & $62.6 \pm 10.4$ \\
Remifentanil dose $(\mu \mathrm{g})$ & $63.5 \pm 5.4$ & $65.3 \pm 6.1$ & $62.6 \pm 5.0$ \\
\hline
\end{tabular}

Values are the number of patients or mean \pm SD. Group S: pretreated with saline and remifentanil infusion at an effect site concentration of $4 \mathrm{ng} / \mathrm{ml}$, Group R: pretreated with saline and remifentanil infusion at an effect site concentration of $2 \mathrm{ng} / \mathrm{ml}$ at first and then this was reset to $4 \mathrm{ng} / \mathrm{ml}$, Group L: pretreated with lidocaine and remifentanil infusion at an effect site concentration of $4 \mathrm{ng} / \mathrm{ml}$. There was no difference between the groups.

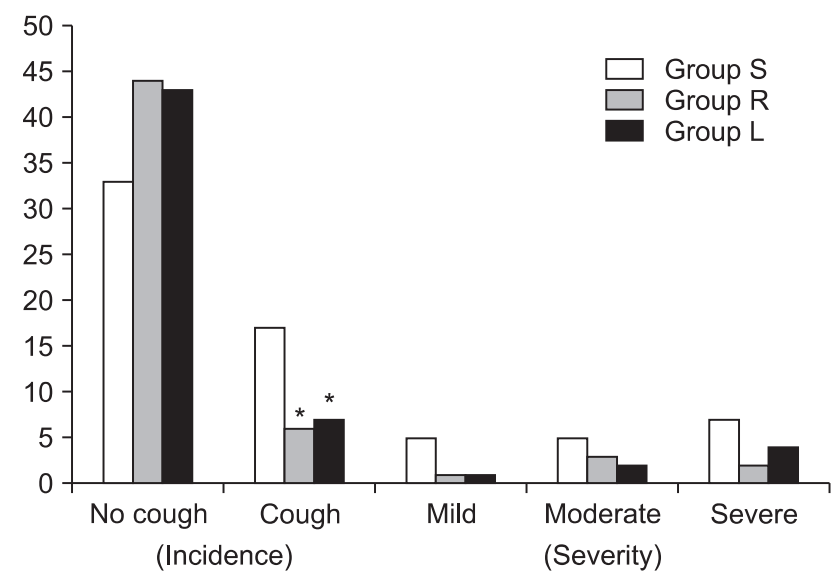

Fig. 1. The incidence and severity of cough after remifentanil infusion. Values are the number of patients. Group S: pretreated with saline and remifentanil infusion at an effect site concentration of 4 $\mathrm{ng} / \mathrm{ml}$, Group R: pretreated with saline and remifentanil infusion at an effect site concentration of $2 \mathrm{ng} / \mathrm{ml}$ at first and then this was reset to $4 \mathrm{ng} / \mathrm{ml}$, Group L: pretreated with lidocaine and remifentanil infusion at an effect site concentration of $4 \mathrm{ng} / \mathrm{ml}$. ${ }^{*} \mathrm{P}<0.05$ compared with Group S.
$\mathrm{R}$ and Group L for the incidence of coughing. There were no significant differences amongst the 3 groups for the cough severity or the onset times of cough $(26.9 \pm 9.2$ vs. $29.1 \pm 8.6$ vs. $22.5 \pm 7.6$, respectively). There were no significant statistical differences among the three groups for the severity of the pain after propofol infusion (Group S had 23 cases with a pain score 0 and 27 cases with a pain score 1, Group R had 22 cases and 27 cases with a pain score 0 and 1 and Group L had 18 cases and 28 cases with a pain score 0 and 1 , respectively) (Table 2).

\section{Discussion}

In this study, we concluded that the incidence of remifentanilinduced coughing during anesthetic induction was reduced by graded escalation of the remifentanil concentration using a TCI pump, and this was as effective as pretreatment with lidocaine 1 $\mathrm{mg} / \mathrm{kg}(\mathrm{P}<0.05)$.

In the present study, when remifentanil's effect site concentration was set at $4.0 \mathrm{ng} / \mathrm{ml}$, the incidence of coughing was $34 \%$, which is slightly higher than that reported by Kim et al. [2,3] who set the effect site concentration at $4.0 \mathrm{ng} / \mathrm{ml}$ and $5.0 \mathrm{ng} / \mathrm{ml}$ and the incidence of coughing was $27.6 \%$ and $27.9 \%$, respectively. The difference is believed to be caused by the different characteristics of the subjects of the two studies. Smokers were excluded in our study, but Kim et al. included them in their report. There have been reports showing that smoking reduced the incidence of fentanyl-induced coughing $[9,10]$. Kim et al. reported that the incidence of remifentanil induced coughing was lower in smokers than that in nonsmokers [2]. Therefore, the higher incidence of coughing in our study is considered to be due to the exclusion of smokers.

Table 2. Pain Score after Propofol Infusion and the Onset Time of Cough after Remifentanil Infusion

\begin{tabular}{cccccc}
\hline \multirow{2}{*}{ Group } & \multicolumn{5}{c}{ Pain score } \\
\cline { 2 - 5 } & 0 & 1 & 2 & 3 & \\
\hline Group S (n=50) & $23(46 \%)$ & $27(54 \%)$ & 0 & 0 & $26.9 \pm 9.2$ \\
Group R (n=50) & $22(44 \%)$ & $27(54 \%)$ & $1(2 \%)$ & 0 & $29.1 \pm 8.6$ \\
Group L (n=50) & $22(44 \%)$ & $28(56 \%)$ & $4(8 \%)$ & 0 & $22.5 \pm 7.6$ \\
\hline
\end{tabular}

Values are the number of patients. Group S: pretreated with saline and remifentanil infusion at an effect site concentration of $4 \mathrm{ng} / \mathrm{ml}$, Group R: pretreated with saline and remifentanil infusion at an effect site concentration of $2 \mathrm{ng} / \mathrm{ml}$ at first and then this was reset to 4 $\mathrm{ng} / \mathrm{ml}$, Group L: pretreated with lidocaine and remifentanil infusion at an effect site concentration of $4 \mathrm{ng} / \mathrm{ml}$. Pain score 0 : negative response to question, 1: pain in response to questioning only without any behavioral signs, 2: pain in response to questioning and accompanied by behavioral signsor pain reported spontaneously without questioning, 3: strong vocal response or response accompanied by facial grimacing, arm withdrawal or tears. There was no difference in the pain score after propofol infusion and the onset time of cough after remifentanil infusion between the groups. 
The exact mechanism of opioid-induced coughing is not known, but some probable causes have been suggested. Opioids block the outflow of the central nervous system and activate the vagal nerve, which causes coughing and reflex bronchial constriction. The suppression of the fentanyl-induced cough reflex after the inhalation of bronchodilators (terbutaline and salbutamol) supports the theory of bronchial constriction $[6,7,11]$. Moreover, although fentanyl hardly causes the release of histamine, the histamines released from pulmonary mastcells have been reported to be the cause of fentanyl-induced coughing [12]. A different mechanism is that opioids constrict the bronchial smooth muscle and this causes remodeling of the bronchial wall. This stimulates the receptors, which trigger the cough reflex via the vagal afferent pathway [13].

Intravenous infusion of lidocaine is known to suppress the cough reflex as well as all of the mechanically-induced and chemically-induced airway reflexes [14-16]. Pandey et al. [17] asserted that the minimum dose of lidocaine to suppress fentanyl-induced coughing is $0.5 \mathrm{mg} / \mathrm{kg}$, but further increasing the amount does not decrease the incidence of fentanylinduced coughing. However, Lin et al. [8] argued that lidocaine $2 \mathrm{mg} / \mathrm{kg}$ effectively suppresses fentanyl-induced coughing. In the present study, we tried to suppress the remifentanilinduced coughing by pretreating the patient with lidocaine 1 $\mathrm{mg} / \mathrm{kg}$. The coughing was reduced from $34 \%$ to $14 \%$, which is similar to the results of Pandey et al. However, it is not possible to know if this was the optimal lidocaine dose for preventing remifentanil-induce coughing. Further study is required on the optimal lidocaine dose.

Lin et al. [9] reported that fentanyl-induced coughing can be reduced by solely decreasing the infusion rate of fentanyl without the pretreatment with other drugs. Bailey also reported that the cough reflex after the administration of opioids is partly related to the circulation time, which can be a clinical clue to determine the 'vein-to-brain' time and the cardiac output [18]. From a pharmacological perspective, the length of the drug infusion time can affect the peak plasma concentration. As the infusion time is prolonged, the peak plasma concentration is lowered. The threshold of remifentanil-induced coughing is more easily reached at a high peak plasma concentration. Therefore, prolonging the infusion time can decrease remifentanil-induced coughing. In this study, we used a TCI pump to have remifentanil reach the effect site concentration of $2.0 \mathrm{ng} / \mathrm{ml}$. Then we increased the remifentanil in phases up to $4.0 \mathrm{ng} / \mathrm{ml}$. As a result, the incidence of coughing was reduced from $34 \%$ to $12 \%$. We can infer this occurred because Group R had a lower peak plasma concentration than that of Group S.

The incidence of pain caused by propofol for anesthetic induction varies from $28-90 \%$ [19]. Remifentanil and lidocaine are known to reduce pain [20]. In this study, we administered remifentanil at a concentration of $4 \mathrm{ng} / \mathrm{ml}$ and we pretreated the patients with lidocaine and normal saline. The incidence of propofol induced pain was around $54-64 \%$ with no significant differences amongst the three groups. To prevent propofol induced pain, remifentanil or lidocaine had no additive/ synergistic effect, and lidocaine had no significant effect. More studies on the dosage of the two drugs and their additive and synergistic effects are needed.

In conclusion, graded escalation of the remifentanil concentration when performing anesthetic induction reduced the remifentanil induced coughing as effectively as lidocaine 1 $\mathrm{mg} / \mathrm{kg}$ pretreatment. So, it is believed that the graded escalation of the remifentanil concentration alone without pretreatment with any other drugs can effectively suppress the incidence of coughing.

\section{Acknowledgements}

This article was presented at the 86th annual scientific meeting of the Korean Society of Anesthesiologists.

\section{References}

1. Scott LJ, Perry CM. Remifentanil: a review of its use during the induction and maintenance of general anaesthesia. Drugs 2005; 65 : 1793-823.

2. Kim JY, Park KS, Kim JS, Park SY, Kim JW. The effect of lidocaine on remifentanil-induced cough. Anaesthesia 2008; 63: 495-8.

3. Kim JY, Kim JY, Park SY, Jung WS, Kwak HJ. Effect of low dose ketamine to prevent remifentanil-induced cough: a randomized, double-blind, placebo controlled trial. Korean J Anesthesiol 2009; 56: $624-7$

4. Tweed WA, Dakin D. Explosive coughing after bolus fentanyl injection. Anesth Analg 2001; 92: 1442-3.

5. Phua WT, Teh BT, Jong W, Lee TL, Tweed WA. Tussive effect of a fentanyl bolus. Can J Anaesth 1991; 38: 330-4.

6. Lui PW, Hsing $\mathrm{CH}$, Chu YC. Terbutaline inhalation suppresses fentanyl-induced coughing. Can J Anaesth 1996; 43: 1216-9.

7. Agarwal A, Azim A, Ambesh S, Bose N, Dhiraj S, Sahu D, et al. Salbutamol, beclomethasone or sodium chromoglycate suppress coughing induced by iv fentanyl. Can J Anaesth 2003; 50: 297-300.

8. Lin CS, Sun WZ, Chan WH, Lin CJ, Yeh HM, Mok MS. Intravenous lidocaine and ephedrine, but not propofol, suppress fentanylinduced cough. Can J Anaesth 2004; 51: 654-9.

9. Lin JA, Yeh CC, Lee MS, Wu CT, Lin SL, Wong CS. Prolonged injection time and light smoking decrease the incidence of fentanylinduced cough. Anesth Analg 2005; 101: 670-4.

10. Oshima T, Kasuya Y, Okumura Y, Murakami T, Dohi S. Identification of independent risk factors for fentanyl-induced cough. Can J Anaesth 2006; 53: 753-8.

11. Reitan JA, Stengert KB, Wymore ML, Martucci RW. Central vagal control of fentanyl-induced bradycardia during halothane anesthesia. Anesth Analg 1978; 57: 31-6.

12. Flacke JW, Flacke WE, Bloor BC, Van Etten AP, Kripke BJ. Histamine 
release by four narcotics: a double-blind study in humans. Anesth Analg 1987; 66: 723-30.

13. Yasuda I, Hirano T, Yusa T, Satoh M. Tracheal constriction by morphine and by fentanyl in man. Anesthesiology 1978; 49: 117-9.

14. Yukioka H, Yoshimoto N, Nishimura K, Fujimori M. Intravenous lidocaine as a suppressant of coughing during tracheal intubation. Anesth Analg 1985; 64: 1189-92.

15. Poulton TJ, James FM III. Cough suppression by lidocaine. Anesthesiology 1979; 50: 470-2.

16. Nishino T, Hiraga K, Sugimori K. Effects of i.v. lignocaine on airway reflexes elicited by irritation of the tracheal mucosa in humans anaesthetized with enflurane. Br J Anaesth 1990; 64: 682-7.

17. Pandey CK, Raza M, Ranjan R, Singhal V, Kumar M, Lakra A, et al. Intravenous lidocaine $0.5 \mathrm{mg} / \mathrm{kg}$ effectively suppresses fentanylinduced cough. Can J Anaesth 2005; 52: 172-5.

18. Bailey PL. Possible Mechanism(s) of opioid-induced coughing. Anesthesiology 1999; 90: 335.

19. Tan CH, Onsiong MK. Pain on injection of propofol. Anaesthesia 1998; 53: 468-76.

20. Roehm KD, Piper SN, Maleck WH, Boldt J. Prevention of propofolinduced injection pain by remifentanil: a placebo-controlled comparison with lidocaine. Anaesthesia 2003; 58: 165-70. 